Original article

\title{
Changes in plasma fatty acid composition are associated with improvements in obesity and related metabolic disorders:
} A therapeutic approach to overweight adolescents

\author{
Marcela Guerendiain ${ }^{\mathrm{a}, \mathrm{b}}$, Rosa Montes ${ }^{\mathrm{a}, \mathrm{f}}$, Gemma López-Belmonte ${ }^{\mathrm{c}}$, \\ Miguel Martín-Matillas d, e, Ana I. Castellote ${ }^{\mathrm{a}, \mathrm{f}}$, Elena Martín-Bautista ${ }^{\mathrm{d}}$, Amelia Martí ${ }^{\mathrm{f}, \mathrm{g}}$, \\ J. Alfredo Martínez ${ }^{\mathrm{f}, \mathrm{g}}$, Luis Moreno ${ }^{\mathrm{h}}$, Jesús $\mathrm{M}^{\mathrm{a}}$ Garagorri $^{\mathrm{h}}$, Julia Wärnberg ${ }^{\mathrm{i}}$, \\ Javier Caballero ${ }^{\mathrm{j}}$, Ascensión Marcos ${ }^{\mathrm{i}}$, M. Carmen López-Sabater ${ }^{\mathrm{a}, \mathrm{f}, \text { * }}$, \\ Cristina Campoy ${ }^{c, d, k}$, EVASYON Study Group \\ a Department of Nutrition and Food Science, Faculty of Pharmacy, University of Barcelona, Barcelona, Spain \\ b University of the Republic, Montevideo, Uruguay \\ ${ }^{\mathrm{c}}$ Instituto de Investigación Biosanitaria (Ibs Granada), Department of Paediatrics, University of Granada, Granada, Spain \\ ${ }^{\mathrm{d}}$ EURISTIKOS Excellence Centre for Paediatric Research, Granada, Spain \\ e Department of Physical Education and Sport, School of Sport Sciences, University of Granada, Spain \\ ${ }^{\mathrm{f}}$ CIBER Physiopathology of Obesity and Nutrition (CIBEROBN), Institute of Health Carlos III, Spain \\ g Department of Nutrition, Food Science, Physiology and Toxicology, University of Navarra, Pamplona, Spain \\ ${ }^{\mathrm{h}}$ Department of Paediatrics, Radiology and Physical Medicine, University of Zaragoza, Spain \\ i Department of Metabolism and Nutrition, Institute of Food Science, Technology and Nutrition (ICTAN), Spanish National Research Council (CSIC), Madrid, \\ Spain \\ j Biochemical Service, Hospital Reina Sofía, Córdoba, Spain \\ k CIBER de Epidemiología y Salud Pública (CIBERESP), Granada, Spain
}

\section{A R T I C L E I N F O}

Article history:

Received 19 February 2016

\section{Keywords:}

Adiposity

Cardiometabolic profile

Weight loss
Accepted 2 November 2016

Plasma fatty acids

Obese adolescents

\section{S U M M A R Y}

Background \& aims: In recent years, obesity has reached alarming levels among children and adolescents. The study of plasma fatty acid (FA) composition, as a reflection of diet, and its associations with other parameters, that are closely linked to obesity and the cardiometabolic profile, may be useful for setting nutritional goals for obesity treatment and prevention. This study explored the relationship between plasma FA levels and body fat and cardiometabolic risk markers, in overweight adolescents. Methods: A multidisciplinary weight loss program was followed by 127 overweight and obese adolescents aged 12-17 years old. Plasma FA composition, anthropometric indicators of adiposity and biochemical parameters were analyzed at baseline, two months (the end of the intensive intervention phase) and six months (the end of the extensive phase).

Results: While saturated fatty acid (SFA) and n-6 polyunsaturated fatty acid (PUFA) levels decreased significantly during the intervention, monounsaturated fatty acid (MUFA) and n-3 PUFA showed the opposite trend. The decrease in SFA C14:0 was associated with a reduction in total and LDL cholesterol, apolipoprotein B and insulin. The increase in MUFAs, especially C18:1n-9, was related to a reduction in weight, fat mass, fat mass index and glucose. Regarding PUFAs, changes in the n-3 series were not associated with any of the parameters studied, whereas the reduction in n-6 PUFAs was directly related to weight, fat mass, total and HDL cholesterol, apolipoprotein A1, glucose and insulin, and inversely associated with diastolic blood pressure. The adolescents with greater weight loss presented significant changes in MUFAs, n-6 PUFAs and C14:0.

Conclusions: Modifications in plasma FA composition were associated with adiposity reduction and cardiometabolic profile improvement in an anti-obesity program aimed at adolescents. The changes

Abbreviations: apoA1, apolipoprotein A1; apoB, apolipoprotein B; BMI, body mass index; CRP, C-reactive protein; CVD, cardiovascular diseases; DBP, diastolic blood

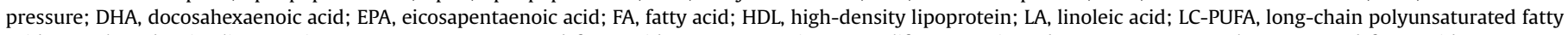

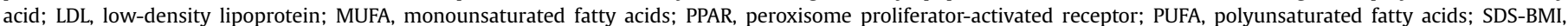
standard deviation score of BMI; SFA, saturated fatty acids; TAG, triacylglycerols; VLDL, very-low-density lipoprotein.

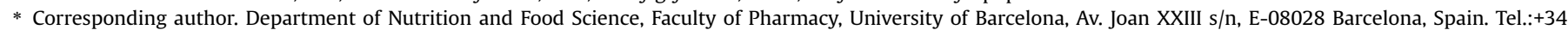
934024512

E-mail address: mclopez@ub.edu (M.C. López-Sabater).

http://dx.doi.org/10.1016/j.clnu.2016.11.006

0261-5614/@ 2016 Elsevier Ltd and European Society for Clinical Nutrition and Metabolism. All rights reserved. 
observed in FA composition were related to the success of the treatment, since the individuals most affected by these variations were those who presented the greatest weight loss.

๑) 2016 Elsevier Ltd and European Society for Clinical Nutrition and Metabolism. All rights reserved.

\section{Introduction}

Obesity in early life has become a matter of concern for health organizations worldwide, since it is an extremely prevalent disorder in developed countries and is reaching alarming values in developing countries [1]. Being overweight is a key risk factor for several disorders, especially cardiovascular disease (CVD), but also type-2 diabetes, dyslipidemia and inflammation [2]. The relationship between obesity and other diseases in children and adolescents has been investigated at length [3]. It has been found that obese children present a higher degree of oxidative stress and systemic inflammation than their normal-weight counterparts. Dietary and multidisciplinary interventions may induce changes in this metabolic and inflammatory state [4].

In obese people, the fatty acid (FA) composition of blood and tissue changes and affects some important physiological functions related to body fat. Overweight adolescents have higher levels of saturated fatty acids (SFAs) [5] and lower levels of monounsaturated fatty acids (MUFAs) [6], docosahexaenoic acid (C22:6n-3, DHA) and total n-3 polyunsaturated fatty acids (PUFAs) [5] than normal-weight adolescents. The FA composition of plasma lipids reflects dietary fat intake. Thus, diet and lifestyle interventions may be effective in preventing the development of obesity and associated disorders [7].

Several studies have established that an elevated intake of SFA has adverse effects on health, since they cause white adipose tissue expansion, increase oxidative stress and inflammation, impair insulin signaling and cause insulin resistance in multiple tissues [8]. By contrast, MUFA consumption reduces adipocyte size [9] and lipogenesis by increasing FA oxidation [7]. Thus, populations with high oleic acid (C18:1 n-9) intake, such as the Mediterranean diet, have a lower prevalence of obesity, type- 2 diabetes and cardiovascular events [10]. It has been suggested that palmitoleic acid (16:1 n-7), other MUFA, has hormone-like properties and improves some metabolic parameters that are impaired in obesity and type 2 diabetes mellitus; however, the results in plasma are still unclear [11].

It has been observed that PUFAs participate in the modulation of several pathways involved in lipoprotein metabolism, thereby influencing blood cholesterol and minimizing insulin resistance [7]. Studies in animals and humans supplemented with n-3 FAs have shown an improvement in insulin sensitivity and a reduction in the secretion of very-low-density lipoprotein (VLDL), apoB degradation and FA oxidation [7]. In addition, dietary n-3 PUFAs are associated with lower levels of inflammation and endothelial activation in cardiovascular disease and other chronic and acute diseases [12].

The present study explored the associations between anthropometric and cardiometabolic parameters and plasma fatty acid levels in overweight and obese adolescents subjected to a multidisciplinary anti-obesity program. The evolution of these parameters was evaluated at different points in the intervention and the degree of weight loss achieved by the last period taken into account. To our knowledge, this is the first study to analyze plasma fatty acid composition according to degree of weight loss in overweight and obese adolescents. Therefore, this trial may be very useful to develop more complete studies to establish dietary regimes aimed at reduce the prevalence of pediatric obesity and associated pathologies.

\section{Materials and methods}

\subsection{Ethics statement}

Written informed consent was obtained from all adolescents and their parents. The study was conducted in accordance with the ethical principles of the Declaration of Helsinki (Hong Kong revision, 1989; Edinburgh revision, 2000; and Seoul revision, 2008), the European Economic Community (EEC) Good Clinical Practice guidelines (document 111/3976/88 of July 1990) and current Spanish law, which regulates clinical research on humans (Royal Decree 561/1993 on clinical trials). This project was also approved by the local ethics committees.

\subsection{Participants and study design}

The study comprised 127 adolescents aged $12-17$ years old and diagnosed as overweight or obese at four hospitals in various Spanish cities (Granada, Madrid, Pamplona and Zaragoza). The inclusion criteria were as follows: overweight or obese, Spanish or educated in Spain, and free from any other diagnosed disease. Adolescents receiving pharmacological treatment or diagnosed with anorexia, bulimia or any other eating disorder, except bingeeating disorder, were excluded. The individuals included were treated as part of the EVASYON Study (development, implementation and evaluation of the efficacy of a therapeutic program for overweight and obese adolescents: comprehensive education on nutrition and physical activity). It comprised a calorie-restricted diet (10-40\%), increased physical activity (at least $60 \mathrm{~min} /$ day, 5 days a week), psychological therapy and nutritional education. The macronutrient distribution was as follow: $50 \%$ of energy from carbohydrates, $30 \%$ from fat and $20 \%$ from proteins.

\subsection{Dietary intake and physical condition}

The study group previously validated 72-h dietary record and a semi-quantitative food-frequency questionnaire, which were applied to assess dietary intake of adolescents. The nutrient consumption was determined using the latest available information in food-composition tables from Spain.

Physical Activity Questionnaire for Adolescents (PAQ-A), Course navette or 20-m Shuttle run test, Handgrip strength and $4 \times 10-\mathrm{m}$ shuttle-run, among others tests and questionnaires were used to evaluate the physical activity.

\subsection{Body composition, pubertal development and resting blood pressure}

The anthropometric measures used in this study were height, weight and skin-fold thicknesses (triceps, biceps, subscapular, suprailiac, thigh and calf), which were measured consecutively in triplicate and averaged. Body mass index was calculated as weight $(\mathrm{kg}) /$ height $\left(\mathrm{m}^{2}\right)$. Body weight was determined without shoes and with light clothing using a standard beam balance. Skin-fold thicknesses were measured on the left side of the body using a Holtain skin-fold calliper.

Pubertal development was assessed in accordance with the 5stage system established by Tanner, and blood pressure was 
obtained using a digital automatic blood pressure monitor (Omron M6, Omron Health Care Co., Ltd., Kyoto, Japan) according to validated procedures.

\subsection{Biochemical and metabolic analysis}

Blood was collected by venepuncture, after an overnight fast, and then was centrifuged. The aliquots of plasma or serum were stored at $-80{ }^{\circ} \mathrm{C}$ until analysis.

Total cholesterol, HDL cholesterol, triacylglycerols (TAG), glucose and C-reactive protein (CRP) were determined using an Olympus AU2700 biochemical autoanalyser (Olympus, Melville, NY, USA). VLDL cholesterol and low-density lipoprotein (LDL) cholesterol were calculated from existing values for cholesterol, HDL cholesterol and triglycerides. Apolipoprotein B (apoB) and A1 (apoA1) and insulin were analyzed by Luminex-100 IS (Integrated System: Luminex Corporation, Austin, TX, USA).

\subsection{Determination of plasma fatty acids}

Plasma fatty acid levels were determined at three different periods: before the treatment started, at two months of intervention and at six months of treatment. Analyses were carried out by fast gas chromatography according to the method developed in our laboratory by Bondía-Pons et al. [13]. One hundred microliters of plasma samples were saponified by adding sodium methylate and heating to $100{ }^{\circ} \mathrm{C}$. After cooling, the samples were esterified with boron trifluoride-methanol reagent (at the same temperature). Once the tubes were cooled, fatty acid methyl esters were isolated by adding $n$-hexane. A saturated sodium chloride solution was then added. Finally, the tubes were centrifuged and, after drying with anhydrous sodium sulfate, the clear $n$-hexane top layer was transferred to an automatic injector vial. Fast gas chromatography analyses were performed on a Shimadzu GC-2010 Gas Chromatograph (Shimadzu, Kyoto, Japan). The injection volume of the sample was $1 \mu \mathrm{L}$. The injector and detector temperatures were kept at $250{ }^{\circ} \mathrm{C}$ and $270{ }^{\circ} \mathrm{C}$, respectively. The identities of sample methyl ester peaks were determined by comparing their relative retention times with those of well-known fatty acid methyl esters standards. Quantification was performed by standard normalization.

\subsection{Statistical analysis}

Results are presented as means \pm standard deviation (SD) or standard error of the mean (SEM). SPSS 20.0 (SPSS Inc., Chicago, IL, USA) was used for statistical analyses. The Kolmogorov-Smirnov test was used to assess the distribution of variables. Changes in clinical or biochemical parameters and plasma fatty acid composition were analyzed by general linear models using the Bonferroni post-hoc correction. To evaluate the relationship between changes in plasma fatty acids and variations in anthropometric indicators of adiposity, blood pressure and biochemical parameters at two and six months of the intervention, linear regression models were applied. The models were adjusted for age, sex, standard deviation score of body mass index (SDS-BMI) and Tanner stages at baseline, changes in lipid and energy intake at six months with respect to the baseline, and the degree of physical activity. It should be noted that the correlations were only analyzed for those variables that changed significantly between each intervention period and the baseline. General linear models were also applied to examine the differences between changes in fatty acid composition and clinical and biochemical parameters at six months of the intervention in the different weight loss groups, with control for potential confounding factors (sex, age, SDS-BMI, Tanner stage and the corresponding variable at baseline, degree of physical activity and changes in lipid and energy intake at six months with respect to the baseline). To determine whether the changes in the parameters analyzed were significant in each weight loss group, estimated marginal means were used. For all analyses, two-sided significance was determined at $P<0.05$.

\section{Results}

The characteristics of the population at baseline are given in Table 1, which also includes anthropometric and biochemical measurements, physical condition and dietary intake. These data were also obtained at two and six months of the intervention. A more detailed study of the evolution of these parameters was published previously [14]. The differences detected in those results have been taken into account to establish the correlations with plasma FA changes.

Table 2 shows plasma FA composition along the intervention period. During the intensive phase, i.e., the first two months, SFA C14:0 (myristic acid) and C18:0 (stearic acid) decreased significantly $(\mathrm{p}<0.01)$, while total MUFAs and, especially, oleic acid presented the opposite trend $(\mathrm{p}<0.001)$. The sum of plasma PUFAs decreased in the first period and remained constant until the end of the intervention $(\mathrm{p}<0.05)$. Among PUFAs, two different behaviors were observed at two months, depending on the series to which

Table 1

Population characteristics and measurements of clinical and biochemical parameters, physical condition and dietary intake at baseline.

\begin{tabular}{|c|c|c|}
\hline Characteristics & $\mathrm{N}$ & Values \\
\hline Sex, male (\%) & 127 & 44.5 \\
\hline Age (years) & 127 & $14.16 \pm 1.18$ \\
\hline Tanner stages (\%) & 94 & \\
\hline 2 & & 8.5 \\
\hline 3 & & 26.6 \\
\hline 4 & & 42.6 \\
\hline 5 & & 22.3 \\
\hline \multicolumn{3}{|l|}{ Clinical parameters } \\
\hline Weight (kg) & 106 & $85.7 \pm 1.66$ \\
\hline $\operatorname{BMI}\left(\mathrm{kg} / \mathrm{m}^{2}\right)$ & 106 & $31.4 \pm 0.49$ \\
\hline SDS-BMI & 106 & $2.80 \pm 0.05$ \\
\hline Waist circumference $(\mathrm{cm})$ & 97 & $99.0 \pm 1.24$ \\
\hline Body fat $(\%)$ & 93 & $35.8 \pm 0.47$ \\
\hline Body fat (kg) & 92 & $30.8 \pm 0.80$ \\
\hline FMI $\left(\mathrm{kg} / \mathrm{m}^{2}\right)$ & 90 & $11.2 \pm 0.28$ \\
\hline FFM $(\%)$ & 93 & $64.2 \pm 0.47$ \\
\hline Systolic blood pressure (mm Hg) & 80 & $123.4 \pm 1.60$ \\
\hline Diastolic blood pressure (mm Hg) & 80 & $72.6 \pm 1.29$ \\
\hline \multicolumn{3}{|l|}{ Biochemical parameters } \\
\hline Glucose (mmol/L) & 97 & $4.63 \pm 0.04$ \\
\hline Insulin $(\mu \mathrm{UI} / \mathrm{mL})$ & 20 & $18.8 \pm 3.00$ \\
\hline Cholesterol (mmol/L) & 106 & $4.01 \pm 0.06$ \\
\hline HDL-cholesterol (mmol/L) & 104 & $1.15 \pm 0.03$ \\
\hline LDL-cholesterol (mmol/L) & 104 & $2.34 \pm 0.06$ \\
\hline Triacylglycerol (mmol/L) & 106 & $1.01 \pm 0.05$ \\
\hline Apolipoprotein A1 (mg/dL) & 73 & $117.14 \pm 2.16$ \\
\hline Apolipoprotein B (mg/dL) & 73 & $69.93 \pm 2.06$ \\
\hline ApoB/apoA1 ratio & 73 & $0.62 \pm 0.19$ \\
\hline C-reactive protein $(\mathrm{mg} / \mathrm{L})$ & 58 & $3.26 \pm 0.43$ \\
\hline \multicolumn{3}{|l|}{ Physical condition } \\
\hline Hand grip strength (Kg) & 107 & $29.12 \pm 7.78$ \\
\hline Agility (seconds) & 106 & $13.62 \pm 1.53$ \\
\hline Cardiorespiratory endurance (periods) & 98 & $3.07 \pm 1.52$ \\
\hline \multicolumn{3}{|l|}{ Dietary intake } \\
\hline Energy (Kcal/d) & 113 & $3336.87 \pm 1613.99$ \\
\hline Carbohydrates (g/d) & 113 & $362.9 \pm 181.09$ \\
\hline Proteins $(\mathrm{g} / \mathrm{d})$ & 113 & $130.81 \pm 59.27$ \\
\hline Lipids (g/d) & 113 & $151.04 \pm 84.42$ \\
\hline Total fiber (g/d) & 113 & $27.05 \pm 13.01$ \\
\hline
\end{tabular}

Results expressed in mean \pm SEM values. BMI, body mass index; SDS-BMI, standard deviation score of BMI; FMI, fat mass index; FFM, fat free mass; ApoB/apoA1 ratio, apolipoprotein $\mathrm{B} /$ apolipoprotein $\mathrm{A} 1$ ratio. 
Table 2

Plasma fatty acid composition at baseline and during the intervention.

\begin{tabular}{lllll}
\hline Fatty Acids & $\begin{array}{l}\text { Baseline } \\
(\mathrm{n}=127)\end{array}$ & $\begin{array}{l}2 \text { months } \\
(\mathrm{n}=127)\end{array}$ & $\begin{array}{l}6 \text { months } \\
(\mathrm{n}=50)\end{array}$ & $P$ \\
\hline SFA (\%) & $29.96 \pm 2.14$ & $29.77 \pm 1.99$ & $29.52 \pm 1.49$ & 0.676 \\
C14:0 & $0.59 \pm 0.25^{\mathrm{a}}$ & $0.47 \pm 0.15^{\mathrm{b}}$ & $0.50 \pm 0.19^{\mathrm{a}, \mathrm{b}}$ & 0.001 \\
C15:0 & $0.14 \pm 0.03$ & $0.13 \pm 0.03$ & $0.14 \pm 0.03$ & 0.433 \\
C16:0 & $22.06 \pm 1.70^{\mathrm{a}, \mathrm{b}}$ & $22.62 \pm 1.52^{\mathrm{a}}$ & $22.21 \pm 1.63^{\mathrm{b}}$ & 0.039 \\
C17:0 & $0.22 \pm 0.36$ & $0.21 \pm 0.03$ & $0.22 \pm 0.03$ & 0.054 \\
C18:0 & $6.96 \pm 0.74^{\mathrm{a}}$ & $6.31 \pm 0.66^{\mathrm{b}}$ & $6.45 \pm 0.74^{\mathrm{b}}$ & 0.004 \\
MUFA (\%) & $23.30 \pm 3.11^{\mathrm{a}}$ & $24.28 \pm 2.91^{\mathrm{b}}$ & $24.28 \pm 2.95^{\mathrm{b}}$ & $<0.001$ \\
C16:1 n-7 & $1.34 \pm 0.43^{\mathrm{a}, \mathrm{b}}$ & $1.37 \pm 0.37^{\mathrm{a}}$ & $1.26 \pm 0.40^{\mathrm{b}}$ & 0.031 \\
C18:1 n-9 & $21.85 \pm 2.92^{\mathrm{a}}$ & $22.94 \pm 2.84^{\mathrm{b}}$ & $22.89 \pm 2.75^{\mathrm{b}}$ & $<0.001$ \\
C20:1 n-9 & $0.11 \pm 0.03^{\mathrm{a}}$ & $0.11 \pm 0.03^{\mathrm{a}}$ & $0.13 \pm 0.03^{\mathrm{b}}$ & 0.012 \\
PUFA (\%) & $46.74 \pm 4.04^{\mathrm{a}}$ & $45.96 \pm 3.83^{\mathrm{b}}$ & $46.14 \pm 3.56^{\mathrm{b}}$ & 0.013 \\
C20:3 n-9 & $0.09 \pm 0.03^{\mathrm{a}}$ & $0.08 \pm 0.02^{\mathrm{b}}$ & $0.09 \pm 0.02^{\mathrm{b}}$ & 0.025 \\
$n-6$ & $43.80 \pm 4.03^{\mathrm{a}}$ & $42.56 \pm 3.88^{\mathrm{b}}$ & $43.03 \pm 3.71^{\mathrm{b}}$ & 0.004 \\
C18:2 n-6 & $33.83 \pm 3.86^{\mathrm{a}}$ & $32.97 \pm 3.47^{\mathrm{b}}$ & $33.16 \pm 3.56^{\mathrm{b}}$ & 0.021 \\
C20:2 n-6 & $0.18 \pm 0.05^{\mathrm{a}}$ & $0.16 \pm 0.04^{\mathrm{b}}$ & $0.17 \pm 0.04^{\mathrm{a}, \mathrm{b}}$ & 0.009 \\
C18:3 n-6 & $0.34 \pm 0.12^{\mathrm{a}}$ & $0.27 \pm 0.11^{\mathrm{b}}$ & $0.29 \pm 0.09^{\mathrm{b}}$ & 0.002 \\
C20:3 n-6 & $1.60 \pm 0.37^{\mathrm{a}}$ & $1.27 \pm 0.32^{\mathrm{b}}$ & $1.41 \pm 0.35^{\mathrm{c}}$ & 0.032 \\
C20:4 n-6 & $7.36 \pm 1.42$ & $7.51 \pm 1.51$ & $7.56 \pm 1.38$ & 0.157 \\
C22:4 n-6 & $0.34 \pm 0.11$ & $0.28 \pm 0.24$ & $0.25 \pm 0.11$ & 0,068 \\
C22:5 n-6 & $0.15 \pm 0.06^{\mathrm{a}}$ & $0.13 \pm 0.05^{\mathrm{b}}$ & $0.14 \pm 0.05^{\mathrm{a}, \mathrm{b}}$ & $<0.001$ \\
$n-3$ & $2.84 \pm 0.89^{\mathrm{a}}$ & $3.33 \pm 1.08^{\mathrm{b}}$ & $3.02 \pm 0.96^{\mathrm{a}, \mathrm{b}}$ & $<0.001$ \\
C18:3 n-3 & $0.21 \pm 0.07$ & $0.22 \pm 0.08$ & $0.21 \pm 0.06$ & 0.193 \\
C20:5 n-3 & $0.36 \pm 0.32^{\mathrm{a}}$ & $0.47 \pm 0.40^{\mathrm{b}}$ & $0.42 \pm 0.36^{\mathrm{a}, \mathrm{b}}$ & 0.010 \\
C22:5 n-3 & $0.33 \pm 0.10$ & $0.35 \pm 0.09$ & $0.35 \pm 0.11$ & 0.537 \\
C22:6 n-3 & $1.94 \pm 0.58^{\mathrm{a}}$ & $2.28 \pm 0.67^{\mathrm{b}}$ & $2.04 \pm 0.62^{\mathrm{a}, \mathrm{b}}$ & $<0.001$ \\
n-6/n-3 ratio & $18.45 \pm 5.21^{\mathrm{a}}$ & $15.48 \pm 5.22^{\mathrm{b}}$ & $15.76 \pm 4.66^{\mathrm{b}}$ & 0.038 \\
\hline
\end{tabular}

Values expressed as mean \pm SD. Different superscript letters means that differences are statistically different, $\mathrm{p}<0.05$ in a general linear model with Bonferroni posthoc correction. SFA, saturated fatty acids; MUFA, monounsaturated fatty acids; PUFA, polyunsaturated fatty acids.

they belonged. First, plasma n-6 PUFAs decreased ( $p<0.05$ ), except plasma arachidonic acid (C20:4 n-6) and C22:4 n-6. Second, total plasma n-3 PUFAs ( $\mathrm{p}<0.001$ ) and, the main $n-3$ long-chain polyunsaturated FAs (LC-PUFAs), EPA and DHA increased significantly $(p<0.01)$. Consequently, the $n-6 / n-3$ ratio decreased $(p<0.05)$. At the end of the program, total MUFA and oleic acid levels were still higher than baseline values, while levels of stearic acid, total n-6 PUFA, linoleic acid (C18:2 n-6, LA) and C18:3 n- 6 and the n-6/n-3 ratio continued to decrease. By contrast, myristic acid, C20:2 n-6, C22:5 n-6 and n-3 PUFAs presented intermediate levels between baseline and two months.

The relationships between plasma FAs (only those that changed significantly during the treatment) and the anthropometric and biochemical parameters of the population at two months are shown in Table 3. It was observed that the decrease in plasma myristic acid was associated with a reduction in cholesterol $(0.608$, $\mathrm{p}<0.001)$, HDL cholesterol $(0.326, \mathrm{p}<0.05)$, LDL cholesterol $(0.397$, $\mathrm{p}<0.05)$, apoB (0.494, $\mathrm{p}<0.05)$ and insulin $(1.151, \mathrm{p}<0.05)$. The increase in plasma MUFAs, especially C18:1n-9, was inversely associated with weight $(-0.340, \mathrm{p}<0.05)$, body fat $(-0.399$, $\mathrm{p}<0.05)$, fat mass index $(-0.329, \mathrm{p}<0.05)$, glucose $(-0.338$, $\mathrm{p}<0.05)$ and HDL cholesterol $(-0.320, \mathrm{p}<0.05)$. Regarding plasma PUFAs, the variations in $n-3$ series FAs were not associated with any of the factors studied, whereas the reduction in n-6 PUFAs was directly related to weight, body fat, glucose $(p<0.05)$, cholesterol $(\mathrm{p}<0.01)$, HDL cholesterol and apoA1 ( $<<0.05)$, but its association with diastolic blood pressure (DBP) was negative $(-0.288$, $\mathrm{p}<0.05)$. In addition, the reduction in the $n-6 / n-3$ ratio was positively correlated with HDL cholesterol $(0.329, \mathrm{p}<0.05)$ and apoA1 (0.475, p < 0.05).

At six months of treatment (Table 4), in contrast to two months, total plasma MUFAs and oleic acid presented no relationship with any of the adiposity anthropometric indicators or cardiometabolic

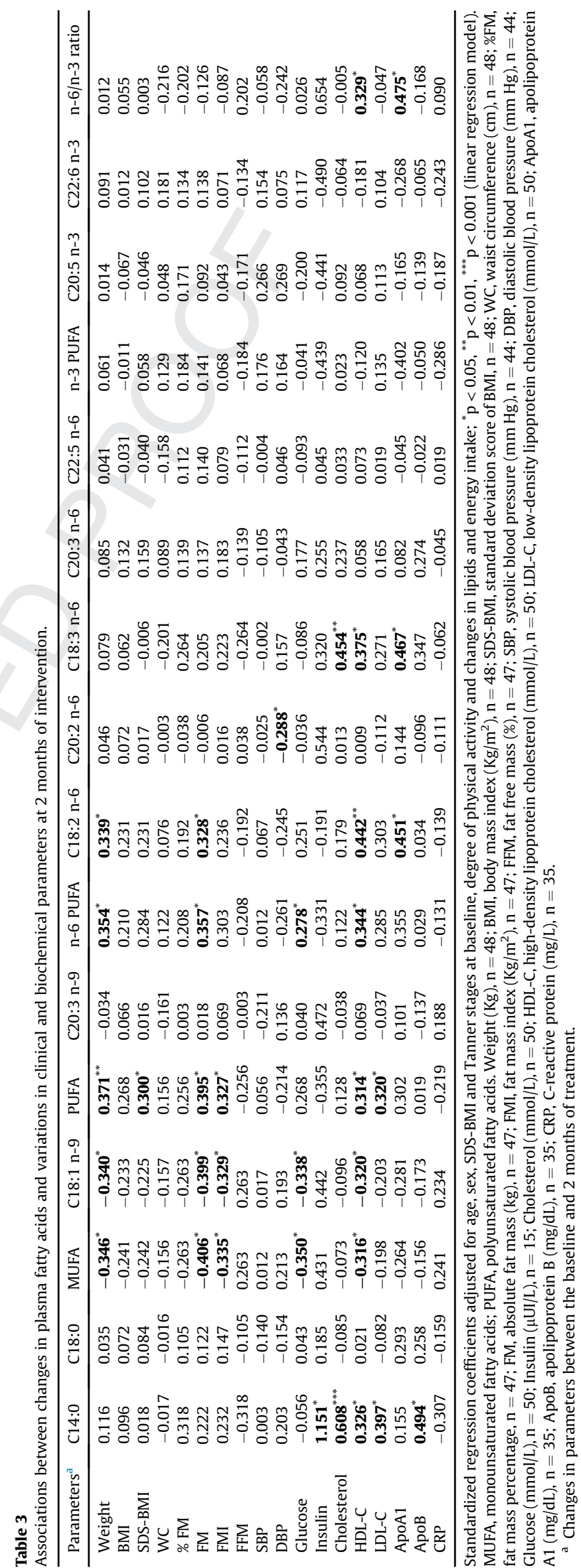


Table 4

Associations between changes in plasma fatty acids and variations in clinical and biochemical parameters at 6 months of treatment.

\begin{tabular}{|c|c|c|c|c|c|c|c|c|c|c|c|}
\hline Parameters $^{\mathrm{a}}$ & C18:0 & MUFA & C18:1n-9 & $\mathrm{C} 20: 1 \mathrm{n}-9$ & PUFA & C20:3n-9 & n-6 PUFA & C18:2n-6 & C18:3n-6 & $C 20: 3 n-6$ & n-6/n-3 ratio \\
\hline Weight & -0.155 & 0.100 & 0.058 & -0.052 & -0.033 & $-0.352^{*}$ & -0.022 & 0.031 & 0.010 & -0.013 & -0.031 \\
\hline BMI & -0.119 & 0.072 & 0.039 & -0.014 & 0.025 & -0.330 & 0.050 & 0.104 & 0.082 & 0.051 & 0.055 \\
\hline SDS-BMI & -0.067 & 0.011 & -0.031 & 0.083 & 0.037 & $-0.377^{*}$ & 0.059 & 0.093 & 0.080 & 0.029 & 0.062 \\
\hline WC & 0.056 & 0.005 & -0.035 & 0.127 & -0.068 & -0.177 & 0.000 & 0.016 & -0.012 & -0.009 & 0.094 \\
\hline$\% \mathrm{FM}$ & -0.026 & -0.029 & -0.081 & 0.141 & 0.068 & $-0.457^{*}$ & 0.102 & 0.183 & 0.122 & -0.028 & 0.036 \\
\hline FM & -0.141 & 0.083 & 0.032 & -0.006 & -0.004 & $-0.417^{*}$ & 0.021 & 0.097 & 0.070 & -0.013 & -0.016 \\
\hline FMI & -0.124 & 0.078 & 0.027 & 0.032 & 0.017 & $-0.420^{*}$ & 0.057 & 0.134 & 0.129 & 0.032 & 0.057 \\
\hline FFM & 0.026 & 0.029 & 0.081 & -0.141 & -0.068 & $0.457^{*}$ & -0.102 & -0.183 & -0.122 & 0.028 & -0.036 \\
\hline SBP & 0.040 & 0.112 & 0.126 & -0.252 & -0.091 & -0.149 & -0.058 & 0.004 & 0.124 & -0.035 & -0.033 \\
\hline DBP & 0.086 & -0.179 & -0.200 & 0.151 & 0.169 & -0.114 & 0.096 & 0.056 & 0.105 & -0.014 & -0.149 \\
\hline Insulin & 0.338 & -0.617 & -0.618 & 0.549 & 1.143 & 0.669 & $0.977^{*}$ & $0.978^{*}$ & 0.593 & 0.279 & $0.927^{*}$ \\
\hline Cholesterol & 0.197 & -0.059 & 0.069 & -0.182 & -0.048 & -0.206 & 0.126 & 0.279 & 0.272 & 0.067 & $0.498^{*}$ \\
\hline HDL-C & 0.355 & -0.170 & -0148 & 0.004 & 0.028 & 0.100 & 0.152 & 0.311 & 0.270 & 0.165 & $0.472^{*}$ \\
\hline LDL-C & 0.124 & -0.175 & -0.175 & -0.077 & 0.119 & -0.078 & 0.262 & 0.344 & 0.165 & 0.052 & $0.439^{*}$ \\
\hline TAG & -0.065 & 0.376 & 0.319 & $-0.399^{*}$ & $-0.427^{*}$ & $-0.587^{* *}$ & -0.328 & -0.209 & 0.186 & -0.093 & 0.087 \\
\hline ApoA1 & 0.078 & 0.019 & 0.094 & $0.761^{*}$ & 0.247 & 0.148 & 0.282 & 0.340 & -0.091 & 0.126 & $0.585^{*}$ \\
\hline AроB & -0.205 & -0.331 & -0.400 & -0.146 & 0.209 & -0.214 & 0.243 & 0.191 & -0.165 & -0.297 & 0.213 \\
\hline CRP & -0.377 & 0.131 & -0.002 & -0.167 & -0.221 & -0.265 & -0187 & -0.262 & -0.063 & -0.223 & -0128 \\
\hline
\end{tabular}

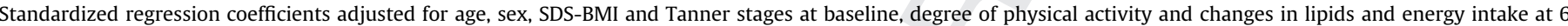
months; ${ }^{*} \mathrm{p}<0.05,{ }^{* *} \mathrm{p}<0.01,{ }^{* * *} \mathrm{p}<0.001$ (linear regression model).

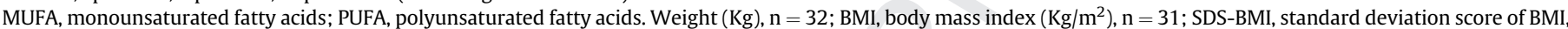

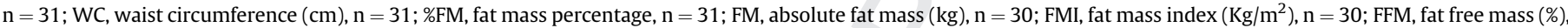

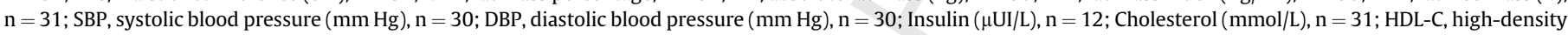

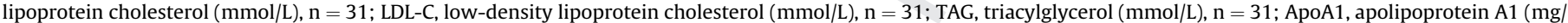
$\mathrm{dL}), \mathrm{n}=19 ; \mathrm{ApoB}$, apolipoprotein $\mathrm{B}(\mathrm{mg} / \mathrm{dL}), \mathrm{n}=19$; CRP, C-reactive protein $(\mathrm{mg} / \mathrm{L}), \mathrm{n}=19$.

a Changes in parameters between the baseline and 6 months of treatment.

risk factors. However, an association was found between the increase in plasma C20:1 n-9 and TAG $(-0.399, \mathrm{p}<0.05)$ and apoA1 (0.761, $\mathrm{p}<0.05)$. Moreover, the reduction in total PUFAs was inversely related to TAG $(-0.427, \mathrm{p}<0.05)$, while the decreases in the $n-6$ series (total n-6 PUFAs and LA) were directly associated with insulin $(p<0.05)$. With regard to the reduction in the $n-6 / n-3$ ratio, the relationships that were identified with insulin $(0.927$, $\mathrm{p}<0.05)$, cholesterol (0.498, p < 0.05), HDL $(0.472, \mathrm{p}<0.05)$ and LDL $(0.439, \mathrm{p}<0.05)$ cholesterol and apoA1 $(0.585, \mathrm{p}<0.05)$ were positive. Interestingly, the increase in plasma C20:3 n-9 was associated with a reduction in weight $(-0.352, \mathrm{p}<0.05)$, SDS-BMI $(-0.377, \mathrm{p}<0.05)$, fat mass percentage $(-0.457, \mathrm{p}<0.05), \mathrm{kg}$ of fat mass $(-0.417, \mathrm{p}<0.05)$, fat mass index $(-0.420, \mathrm{p}<0.05)$ and TAG $(-0.587, \mathrm{p}<0.05)$, as well as a rise in fat-free mass $(0.457$, $\mathrm{p}<0.05)$.

Figure 1 shows the changes in plasma FA composition according to the degree of weight loss in the adolescents, defined as the reduction in SDS-BMI at the end of the intervention. It was established that those who had a reduction in SDS-BMI greater than 0.5 presented the highest changes in plasma FA composition and the most significant differences with respect to the baseline. Thus, this group presented a significant reduction in levels of stearic acid $(\mathrm{p}=0.009)$, total $\mathrm{n}-6$ PUFA $(\mathrm{p}=0.043)$, linoleic acid $(\mathrm{p}=0.049)$ and $\mathrm{C} 18: 3 \mathrm{n}-6(\mathrm{p}=0.011)$ at six months of treatment compared to basal conditions, whereas total MUFA $(p=0.024)$ and oleic acid $(\mathrm{p}=0.016)$ levels showed the opposite behavior. When comparing the values of each plasma FA between the three weight loss groups, differences were observed for myristic acid ( $\mathrm{p}=0.031$ ), with the values detected for the reduction SDS-BMI $>0.5$ group being lower than those of the intermediate group (reduction SDS-BMI 0.25-0.5).

\section{Discussion}

The plasma fatty acid composition of the adolescents under study changed during the intervention, which is consistent with other variations considered favorable for obesity prevention and/or treatment. It may be assumed that the reduction in plasma SFA could be a beneficial effect, since these FA are considered to promote obesity problems and preserve fat mass even after weight loss [15]. On the other hand, MUFA C18:1n-9 and C20:1n-9 plasma content increased, a finding reported by other authors as inversely related to overweight status [10]. With regard to PUFAs, the observed reduction in the plasma n- 6 series and the increase in n-3 levels, especially EPA and DHA, lead to a reduction in the $n-6 / n-3$ ratio and have also been linked in the literature to a lower prevalence of obesity and CVD risk factors [7,16]. However, unexpectedly, C20:4 n- 6 and C22:4 n-6, which are the precursors of the biosynthesis of dihomo-prostaglandin derivatives [17], remained unchanged. It has been described that a high arachidonic acid intake leads to proliferation and differentiation of wait adipose tissue, lower fatty acids oxidation, and insulin and leptin resistance [18]. Also, their metabolites (prostaglandin 2, thromboxane 2 and leukotriene 4) are prothrombotic and proinflammatory effects.

The tendency observed during the second period of intervention of plasma C14:0, C20:2n-6, C22:5n-6, total n-3 PUFAs, EPA and DHA to return to baseline values could be explained by the lower frequency of medical controls. Thus, the recovery of inappropriate eating habits as a result of reduced observation could be responsible for this step back.

A recent study [19] analyzed tertiles of SFA intake in adolescents undergoing interdisciplinary therapy. The authors indicated that the individuals with a greater reduction in FAs presented decreased levels of insulin, insulin resistance and total and LDL cholesterol. In line with this study and other work [20], we observed that the changes in the different fractions of cholesterol (total cholesterol, HDL and LDL) and fasting insulin were linked to the lower plasma levels of myristic acid. It should be noted that, although other authors did not find any associations between SFAs and apolipoproteins, we observed a direct link with apolipoprotein B. This finding may be useful, because apoB is proatherogenic and is a better predictor of cardiovascular risk than LDL cholesterol and other conventional lipids [21].

Cross-sectional and longitudinal studies have concluded that Mediterranean diets, especially those that include oleic acid, play an important role in body weight maintenance and obesity prevention $[10,22,23]$. It has been proposed that MUFAs promote lipid 

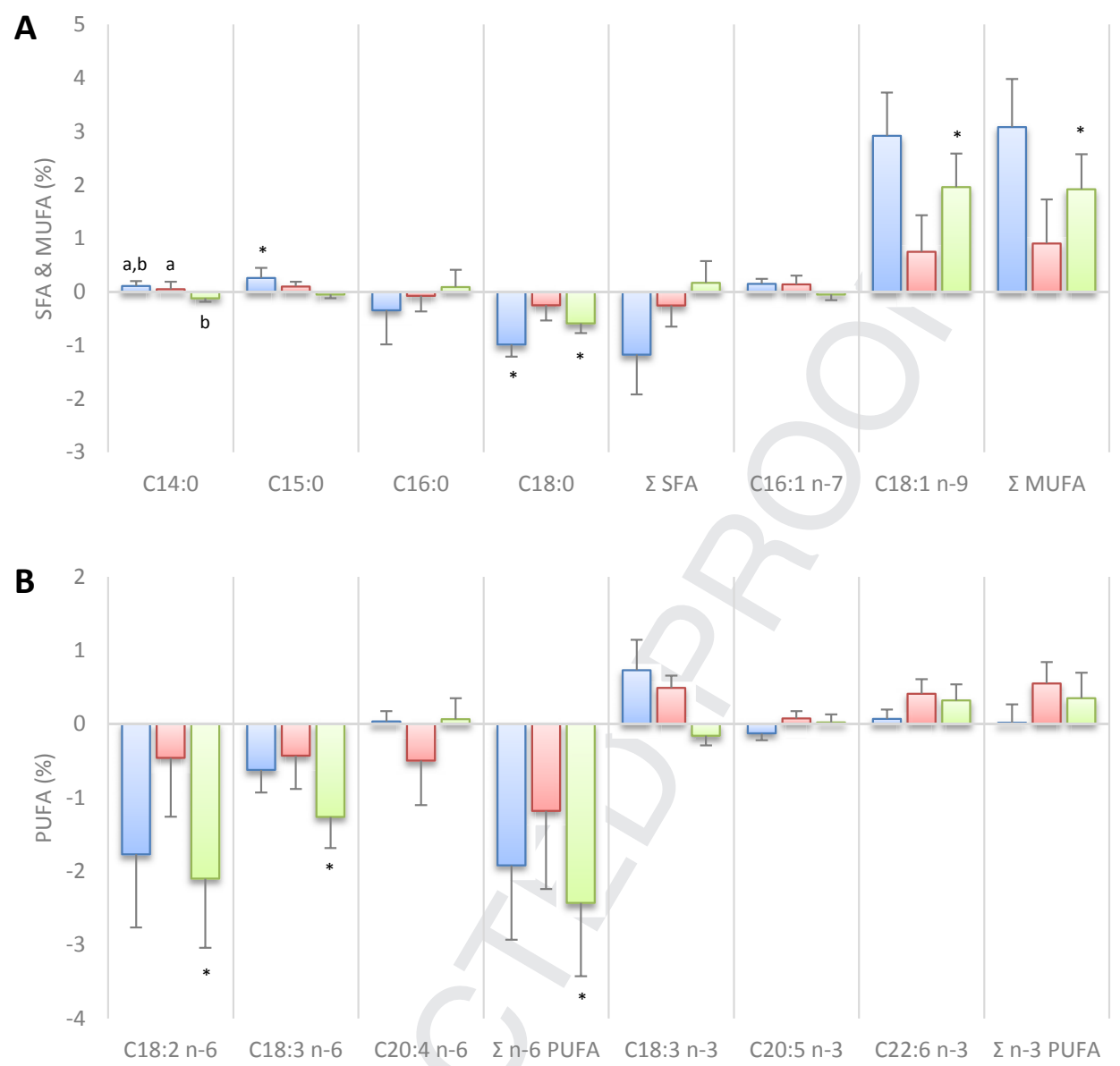

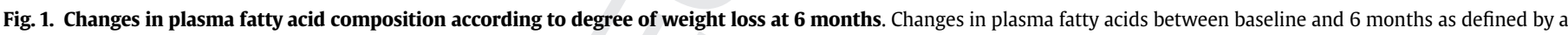

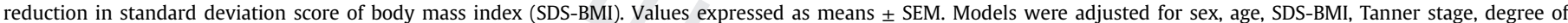

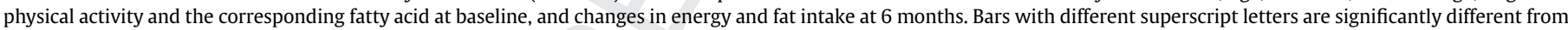

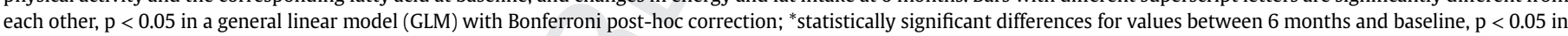

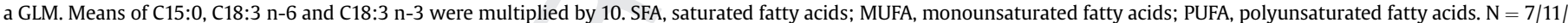
18 for groups SDS-BMI $<0.25$, SDS-BMI $=0.25-0.5$ and SDS-BMI $>0.5$, respectively

oxidation [22] and decrease lipogenesis, which leads to reduced weight and adiposity [7]. However, it is possible that the effect of C18:1 n-9 will be due to the displacement of deleterious properties of SFA than to its own action [24]. Hence, as expected, during the intensive phase of the treatment, it was observed that the increase in these FA levels was related to a decline in adiposity, which was defined by weight, fat mass and fat mass index. Further studies are required to determine if changes in plasma MUFA, mainly as oleic acid, could have a beneficial effect on body composition in adolescents.

Regarding MUFAs and cardiovascular risk markers, the evidence is controversial. In a review and meta-analysis, Schwingshackl et al. [23] did not observe differences in HDL and LDL cholesterol or TAG in individuals subjected to a controlled diet with different MUFA levels. However, other authors have established that these FAs lead to lower LDL [25] or higher HDL cholesterol [26]. In our study, plasma MUFA levels were associated with a reduction in TAG and HDL concentration. By contrast, the rise in plasma C20:1 n-9 was related to an increase in apoA1, which is a lipoprotein that exerts an antiatherogenic effect [2]. On the other hand, the evidence suggests that MUFAs are implicated in a lower prevalence of type-2 diabetes [10], a common disease among people who are obese [2,3]. Precisely, we found that oleic acid and total MUFA plasma levels are related to glucose concentration decrease in adolescents.
As expected, we found that the reduction in total n-6 PUFA levels and linoleic acid in plasma was associated with a decrease in weight and fat mass. It has been reported that LA intake, which leads to arachidonic acid synthesis [16], is related to a higher expression of the genes involved in lipogenesis [27]. In mice fed diets modeled on the 20th-century changes in human LA consumption, Alvheim et al. demonstrated that these variations increase the endocannabinoids associated with higher food intake, feed efficiency and adiposity [16].

With regard to the cardiometabolic profile, we observed that a reduction in plasma LA was associated with a reduction in HDL cholesterol and apoA1, in line with a previous study [28]. We also found that changes in C18:3n-6 ( $\gamma$-linolenic acid) plasma levels were directly related to cholesterol [6], which was beneficial in this case because $\gamma$-linolenic acid levels decreased. Moreover, our findings and those of other authors [23] suggest that changes in plasma n-6 PUFAs are linked to a reduction of diastolic blood pressure in overweight individuals. These results led us to conclude that plasma n-6 PUFAs should be studied in depth, since FAs belonging to the same series may present positive or negative association with cardiometabolic risk markers.

An elevated intake of n-6 PUFAs or diets with a high n-6/n-3 ratio may affect the cell membrane composition of adult individuals by decreasing membrane n-3 PUFAs [29]. Moreover, it has been 
reported that an increase in insulin concentration and resistance is linked to an elevated n-6/n-3 ratio and thus affects insulin sensitivity. In our case, the reduction in total n-6 PUFA and LA plasma levels was related to decline in fasting insulin and glucose concentrations observed during the therapy. We consider that this finding may be important due to the current high prevalence of diseases related to hyperinsulinemia and insulin resistance such as type-2 diabetes, a comorbidity related to obesity, even in adolescence [3].

On the other hand, plasma C20:3 n-9 was correlated to body fatness at 6 months. When the FA increased, the anthropometric indicators of general adiposity had the opposite trend. To our knowledge, these relationships have not been studied in depth and there are no studies that explore the possible causes or mechanisms of our findings. However, considering the definition of essential FA deficiency [30], it could be hypothesized that this association is linked to the lower C18:2 n-6 plasma level, since the increase of C20:3 n-9 was accompanied by a decrease of the linoleic acid. Moreover, given that the C20:3 n-9 is synthetized from C18:1 n-9 and, precisely, oleic acid increased at six months, it should be explored if this relationship is due to the biosynthesis.

In terms of weight loss, the SDS-BMI $>0.5$ group presented the greatest changes in plasma FA composition by the end of the program, as expected. Our study indicates that the overweight and obese adolescents who lost most weight had significant changes in plasma fatty acids. The main variations were observed in n-6 PUFAs and MUFAs, whereas n-3 FAs remained unaltered in all weight loss groups. Interestingly, the reduction in plasma myristic acid and n-6 PUFAs and the increase in oleic acid and total MUFAs in plasma were linked to a higher ponderal decrease. These results may be useful for future projects aimed to develop obesity treatments for adolescents. However, the data need to be confirmed by more complete studies, since we did not obtain similar findings in obese children, adolescents or adults.

The main limitation of this study is the absence of a control group. However, we consider that by taking into account the baseline values for each subject and focusing on the evolution of each parameter, we were able to establish some preliminary conclusions that could prove very useful in larger-scale interventional studies in the future.

The combined study of the variations in plasma FA, anthropometric parameters and cardiometabolic profile at different stages helped shed light on the links between those variables and the effectiveness of the anti-obesity program. The relationships analyzed may be used as tools in the study of adiposity and cardiometabolic profile in adolescents.

In conclusion, we found that the modification in plasma fatty acid composition, especially n-6 PUFAs, MUFAs and myristic acid, is related to changes in adiposity and cardiometabolic risk factors in anti-obesity programs aimed at adolescents.

\section{Funding sources}

This work is part of the EVASYON study funded by the Spanish Ministry of Health and Consumption (Carlos III Institute of Health. FIS. Grant PI 051579).

The EVASYON study has received the award from AESAN (Spanish Agency for Food Security and Nutrition) from the Spanish Ministry of Health and Consumption to the best applied research project in 2009.

\section{Statement of authorship}

M.G., R.M., G.L.B, M.M.M., A.I.C., E.M.B., A.M., J.A.M., L.M., J.M.G., J.W., J.C., A.M., M.C.L.S. and C.C. designed research; M.G. conducted research and wrote the paper; M.G. and R.M. analyzed data; R.M., A.I.C. and M.C.L.S. did a critical review of the manuscript; C.C. and M.C.L.S. had primary responsibility for final content. All authors read and approved the final manuscript.

\section{Conflict of interest}

No conflicts of interest.

\section{Acknowledgments}

We would like to thank all of the participants in the EVASYON study group. We thank the Erasmus Mundus External Cooperation Window, Mundus 17, for the PhD grant to Marcela Guerendiain.

\section{The EVASYON Study Group}

Coordinator: Marcos A.

Local clinical treatment teams and researchers (Principal Investigators are bolded); Granada: Campoy C., López-Belmonte G., Delgado M., Martín-Matillas M., Aparicio V., Carbonell A., Agil A., Silva D.R., Pérez-Ballesteros C., Piqueras M.J., Chillón P., Tercedor P., Martín-Lagos J.A., Martín-Bautista E., Pérez-Expósito M., Garófano M., Aguilar M.J., Fernández-Mayorga A., Sánchez P.; Madrid: Marcos A., Wärnberg J., Puertollano M.A., Gómez-Martínez S., Zapatera B., Nova E., Romeo J., Díaz E.L., Pozo T., Morandé G., Villaseñor A., Madruga D., Muñoz R., Veiga O.L., Villagra A., Martínez-Gómez D., Garcia R.M., Vaquero M.P., Pérez-Granados A.M., Navas-Carretero S.; Pamplona: Martí A., Azcona C., Moleres A., Rendo T., Marqués M., Miranda M.G., Martínez J.A.; Santander: Redondo-Figuero C., García-Fuentes M., DeRufino P., González-Lamuño D., Amigo T., Lanza R., Noriega M.J.; Zaragoza: Garagorri J.M., Moreno L.A., Romero P., De Miguel P., Rodríguez G., Bueno G., Mesana Ma..., Vicente G., Fernández J., Rey-López P., Muro C., Tomás C.; Data management and statistical analysis: Wärnberg J., Calle M.E., Barrios L.

\section{References}

[1] WHO. Population-based prevention strategies for childhood obesity: report of a WHO forum and technical meeting. Geneva: World Health Organization; 2010.

[2] Mathieu P, Lemieux I, Després JP. Obesity, inflammation, and cardiovascular risk. Clin Pharmacol Ther 2010;87:407-16.

[3] Daniels SR, Arnett DK, Eckel RH, Gidding SS, Hayman LL, Kumanyika S, et al. Overweight in children and adolescents: pathophysiology, consequences, prevention, and treatment. Circulation 2005;111:1999-2012.

[4] Youssef H, Groussard C, Pincemail J, Moussa E, Jacob C, Lemoine S, et al. Exercise-induced oxidative stress in overweight adolescent girls: roles of basal insulin resistance and inflammation and oxygen overconsumption. Int J Obes 2009;33:447-55.

[5] Klein-Platat C, Drai J, Oujaa M, Schlienger J-L, Simon C. Plasma fatty acid composition is associated with the metabolic syndrome and low-grade inflammation in overweight adolescents. Am J Clin Nutr 2005;82:1178-84.

[6] Steffen LM, Vessby B, Jacobs Jr DR, Steinberger J, Moran A, Hong CP, et al. Serum phospholipid and cholesteryl ester fatty acids and estimated desaturase activities are related to overweight and cardiovascular risk factors in adolescents. Int J Obes 2008;32:1297-304.

[7] Lottenberg AM, Afonso MdS, Lavrador MSF, Machado RM, Nakandakare ER. The role of dietary fatty acids in the pathology of metabolic syndrome. J Nutr Biochem 2012;23:1027-40.

[8] Kennedy A, Martinez K, Chuang C-C, LaPoint K, McIntosh M. Saturated fatty acid-mediated inflammation and insulin resistance in adipose tissue: mechanisms of action and implications. J Nutr 2009;139:1-4.

[9] Yang Z-H, Miyahara H, Iwasaki Y, Takeo J, Katayama M. Dietary supplementation with long-chain monounsaturated fatty acids attenuates obesityrelated metabolic dysfunction and increases expression of PPAR gamma in adipose tissue in type 2 diabetic KK-Ay mice. Nutr Metab 2013;10:1-10.

[10] Pérez-Martínez P, García-Ríos A, Delgado-Lista J, Pérez-Jimenez F, LópezMiranda J. Mediterranean diet rich in olive oil and obesity, metabolic syndrome and diabetes mellitus. Curr Pharm Des 2011;17:769-77.

[11] Nunes EA, Rafacho A. Implications of palmitoleic acid (palmitoleate) on glucose homeostasis, insulin resistance and diabetes. Curr Drug Targets 2016;17:1-10 
YCLNU2972_proof 15 November 2016 - 8/8

8

[12] Rangel-Huerta OD, Aguilera CM, Mesa MD, Gil A. Omega-3 long-chain polyunsaturated fatty acids supplementation on inflammatory biomakers: a systematic review of randomised clinical trials. Br J Nutr 2012;107: S159-70.

[13] Bondia-Pons I, Castellote AI, Lopez-Sabater MC. Comparison of conventional and fast gas chromatography in human plasma fatty acid determination. J Chromatogr B Anal Technol Boomed Life Sci 2004;809:339-44.

[14] Guerendiain M, Mayneris-Perxachs J, Montes R, López-Belmonte G, MartinMatillas M, Castellote AI, et al. Relation between plasma antioxidant vitamin levels, adiposity and cardio-metabolic profile in adolescents: effects of a multidisciplinary obesity programme. Chin Nutr 2015.

[15] Hariri N, Gougeon R, Thibault L. A highly saturated fat-rich diet is more obesogenic than diets with lower saturated fat content. Nutr Res 2010;30: $632-43$.

[16] Alvheim AR, Made MK, Osei-Hyiaman D, Hong YH, Pawlosky RJ, Madsen L, et al. Dietary linoleic acid elevates endogenous 2-AG and anandamide and induces obesity. Obesity 2012;20:1984-94.

[17] Galano JM, Lee JC, Gladine C, Comte B, Le Guennec JY, Oder C, et al. Nonenzymatic cyclic oxygenated metabolites of adrenic, docosahexaenoic, eicosapentaenoic and alpha-linolenic acids; bioactivities and potential use as biomarkers. Biochim Biophys Acta 2015;1851:446-55.

[18] Simopoulos A. An increase in the omega-6/omega-3 fatty acid ratio increases the risk for obesity. Nutrients 2016;8:128.

[19] Masquio DCL, de Piano A, Campos RMS, Stanches PL, Cannier J, Corgosinho FC, et al. Reduction in saturated fat intake improves cardiovascular risks in obese adolescents during interdisciplinary therapy. Int J Chin Pact 2015;69:560-70.

[20] Kim D, Burt A, Ranchalis J, Jarvik L, Eintracht J, Furlong C, et al. Effects of dietary components on high-density lipoprotein measures in a cohort of 1,566 participants. Nutr Metab 2014;11:44.

[21] Schmidt C, Bergstrom G. Apolipoprotein B and apolipopotein A-I in vascular risk prediction - a review. Gur Pharm Bes 2014;20:6289-98.
[22] Bergouignan A, Momken I, Schoeller DA, Simon C, Blanc Sp. Metabolic fate of saturated and monounsaturated dietary fats: the Mediterranean diet revisited from epidemiological evidence to cellular mechanisms. Prog Lipid Res 2009;48:128-47.

[23] Schwingshackl L, Strasser B, Hoffman G. Effects of monounsaturated fatty acids on cardiovascular risk factors: a systematic review and meta-analysis. Ann Nutr Metal 2011;59:176-86.

[24] Calder PC. Functional roles of fatty acids and their effects on human health. J Parenter Enteral Nutr 2015;39:18S-32S.

[25] van Dijk SJ, Feskens EJM, Bs MB, Helen DWM, Heijligenberg R, Bromhaar MG, et al. A saturated fatty acid-rich diet induces an obesity-linked proinflammatory gene expression profile in adipose tissue of subjects at risk of metabolic syndrome. Am J Chin Nutr 2009;90:1656-64.

[26] Tierney AC, McMonagle J, Shaw DI, Gulseth HL, Hell O, Saris WHM, et al. Effects of dietary fat modification on insulin sensitivity and on other risk factors of the metabolic syndrome-LIPGENE: a European randomized dietary intervention study. Int J Obs 2011;35:800-9.

[27] Muhlhausler BS, Cook-Johnson R, James M, Miljkovic D, Duthoit E, Gibson R. Opposing effects of omega-3 and omega- 6 long chain polyunsaturated Fatty acids on the expression of lipogenic genes in mental and retroperitoneal adipose depots in the rat. J Nuts Metal 2010;2010.

[28] Mayneris-Perxachs J, Guerendiain M, Castellote AI, Estruch R, Coves MI, Fitó $\mathrm{M}$, et al. Plasma fatty acid composition, estimated desaturase activities, and their relation with the metabolic syndrome in a population at high risk of cardiovascular disease. Chin Nutr 2014;33:90-7.

[29] Minihane AM, Brady LM, Lovegrove SS, Lesauvage SV, Williams CM, Lovegrove JA. Lack of effect of dietary n-6:n-3 PUFA ratio on plasma lipids and markers of insulin responses in Indian Asians living in the UK. Eur J Nutr 2005;44:26-32.

[30] Holman RT. Nutritional and metabolic interrelationships between fatty acids. Fed Proc 1964;23:1062-7.

27
28
29
30
3
32
33
34
35
36
37
38
39
40
4
42
43
44
45
46
47
48
49
50
5
52

Please cite this article in press as: Guerendiain M, et al., Changes in plasma fatty acid composition are associated with improvements in obesity and related metabolic disorders: A therapeutic approach to overweight adolescents, Clinical Nutrition (2016), http://dx.doi.org/10.1016/ j.clnu.2016.11.006 